Research Article

\title{
Mechanical Model for Shear Friction Capacity of Concrete at Construction Joints
}

\author{
Seung-Jun Kwon $\mathbb{D},{ }^{1}$ Keun-Hyeok Yang $\mathbb{D}^{2},{ }^{2}$ and Ju-Hyun Mun $^{2}$ \\ ${ }^{1}$ Civil and Environment Engineering, Hannam University, Daejeon, Republic of Korea \\ ${ }^{2}$ Architectural Engineering, Kyonggi University, Suwon, Republic of Korea \\ Correspondence should be addressed to Keun-Hyeok Yang; yangkh@kgu.ac.kr
}

Received 16 January 2018; Revised 31 May 2018; Accepted 2 July 2018; Published 24 July 2018

Academic Editor: Charles C. Sorrell

Copyright (c) 2018 Seung-Jun Kwon et al. This is an open access article distributed under the Creative Commons Attribution License, which permits unrestricted use, distribution, and reproduction in any medium, provided the original work is properly cited.

\begin{abstract}
This study examined the reliability and limitations of code equations for determining the shear friction strength of a concrete interface with construction joints. This was achieved by examining the code equations (ACI 318-14, AASHTO, and fib 2010) and comparing the results predicted by equations with experimental data compiled from 207 push-off specimens (133 rough and 74 smooth construction joints). The integrated mechanical model for the monolithic interface, derived from the upper-bound theorem of concrete plasticity, was also modified to estimate the shear friction strength of the construction joints. The upper limit for shear friction strength was formulated from a concrete crushing failure limit on the strut-and-tie action along the interfacial plane, to avoid overestimating the shear transfer capacity of transverse reinforcement with a high clamping force. Code equations are highly conservative and dispersive in predicting the shear friction strength of rough construction joints and yield large scattering in the data for the ratios between the measured and predicted shear friction strengths. The predictions obtained using the proposed model agreed well with test results, indicating correlating trends with the test results for evaluating the effects of various parameters on the shear friction strength of rough construction joints. According to the proposed model, the values of cohesion and coefficient of friction for concrete could be determined as $0.11\left(f_{\mathrm{c}}^{\prime}\right)^{0.65}$ and 0.64 , respectively, for smooth construction joints and $0.27\left(f_{\mathrm{c}}^{\prime}\right)^{0.65}$ and 0.95 , respectively, for rough construction joints, where $f_{c}^{\prime}$ is the compressive strength of concrete.
\end{abstract}

\section{Introduction}

Shear friction is generally accepted as a major mechanism of load transfer along a concrete-to-concrete interface, which is subjected to simultaneous shear and normal stresses. The crack propagation and failure plane of a member governed by shear friction are concentrated on the interfacial shear plane [1-3]. Despite the fact that the mechanism of shear friction is considerably more complex than that of conventional friction $[4,5]$, the ACI 318-14 provision [6] simply considers that applied shear is mostly transferred by the resistance generated from the friction between the two sliding faces and a clamping force. The clamping force is induced by the transverse reinforcement crossing the interfaces. To calculate the clamping force, the stress of the transverse reinforcement is assumed to have reached its yield point. Therefore, the shear friction strength of concrete interfaces calculated using the equations of the code provisions $[6,7]$ increases in proportion to the clamping force which is commonly expressed as $\rho_{\mathrm{vf}} f_{\mathrm{y}}$, where $\rho_{\mathrm{vf}}$ and $f_{\mathrm{y}}$ are the ratio and yield strength of the interface reinforcing bars, respectively. However, Harries et al. [4] revealed that the stress in a high-strength steel reinforcement (with a yield strength of approximately $700 \mathrm{MPa}$ ) is lower than its yield strength at the ultimate state of concrete interfaces. Kwon et al. [8] examined code safety through comparisons with test results taken from 103 push-off specimens with monolithic interfaces. They concluded that the ACI 318-14 and AASHTO equations yield significant underestimations, whereas the overestimations of AASHTO equation are also frequently observed as $\rho_{\mathrm{vf}} f_{\mathrm{y}}$ is less than $8 \mathrm{MPa}$. In particular, the underestimation and disagreement owing to the use of the AASHTO equation are increased for the interface with smooth construction joints [9]. Overall, code equations that 
are empirically formulated using test data collected under a narrow range of influencing parameters do not sufficiently capture the mechanical diversity of the shear friction capacity of concrete interfaces with different concrete casting times.

Concrete interfaces frequently have a construction joint between the precast element and the cast-in-place concrete or at the surface formed by placing one layer of concrete on an existing layer of hardened concrete. When shear is applied to construction joints, the aggregate interlocking action and tensile resistance of concrete are insignificant along the interfacial plane. Hence, a lower shear friction resistance is inevitable along the construction joints than along the monolithic interfaces with or without initial cracks. However, many of the empirical equations [4, 5, 10-13] used to estimate shear friction strength have been proposed for monolithic interface, based on different experimental programs and the shear friction action associated with the truss model. Thus, test data and analytical approaches for construction joints are relatively insufficient. Code provisions $[6,7]$ specify that compared with that of monolithic interfaces, the coefficient of friction $(\mu)$ must be approximately $30 \%$ lower for smooth construction joints and approximately $60 \%$ lower for rough construction joints. However, there is no explicit experimental or analytical validation of this requirement.

The fib 2010 [14] provision specifies a $16.7 \%$ higher value of $\mu$ for rough construction joints than for smooth construction joints. Mattock [15] reported that the shear transfer due to concrete cohesion is considerably reduced in construction joints compared with the shear transfer that develops along monolithic interfaces in concrete. Santos and Júlio [16] pointed out that the roughness of the concrete substrate should be considered in the design expressions in the form of the coefficients of cohesion and/or friction because the bond strength of concrete-to-to interfaces is significantly affected by their substrate state. However, the cohesion and frictional coefficient of concrete in construction joints are still insufficiently interpreted, particularly for high-strength concrete with smooth surfaces. Moreover, the shear friction strength at overreinforced construction joints needs to be appropriately limited to avoid concrete crushing failure before the transverse reinforcement yield is reached. Most of the code equations do not provide an explicit validation for the upper limit or safety evaluation. Thus, the safety and rationality evaluations of the code equations are quite unsatisfactory for rough and smooth construction joints, although such evaluations for monolithic interfaces have been extensively performed in previous studies $[3,11,15]$.

This study determines the cohesion and frictional coefficients of concrete at smooth and rough construction joints using a mechanical approach derived from the upper-bound theorem of concrete plasticity. The upper limits of the shear friction strength are derived from the state of concrete crushing failure limit on the strut-andtie action along the construction joints to avoid overestimating the shear transfer capacity of a transverse reinforcement with a high clamping force. The reliability and limitation of the code equations $[6,7,14]$ used to determine the shear friction strength of construction joints are also examined through comparisons with the experimental data compiled from different sources. Then, a parametric study is conducted using the proposed model, the AASHTO equation, and the results from the collected database to evaluate the effect of different parameters on the shear friction capacity of construction joints.

\section{Database of Push-Off Specimens with Construction Joints}

A total of 207 push-off specimens (including 133 rough construction joints, and 74 smooth construction joints) compiled from different sources in the literature $[4,5,11,17-25]$ were used to examine the reliability and safety of the code equations and mechanical equations with regard to the effect of the different parameters on the shear friction strength of the construction joints. The distribution of the different parameters in the database is shown in Figure 1. Although the roughness parameters, such as maximum peak-to-valley height, total roughness height, and maximum valley depth, influence the cohesion along the concrete interface [26], most of the literature does not provide the details on the substrate state of the interface. Thus, in the database, an interface with only a steelbrushing treatment is classified as a smooth construction joint, whereas an interface intentionally treated with sand blast with the full amplitude above approximately $1.5 \mathrm{~mm}$ is classified as a rough construction joint, with reference to the surface roughness classification specified in fib 2010 [14].

The test data available for smooth construction joints are relatively limited. All the specimens included in the database were reported to have failed in shear friction owing to a major crack along the interfacial plane. Only a few specimens had no transverse reinforcement crossing the interface. Most of the specimens with smooth construction joints were made of concrete with a high compressive strength (exceeding $55 \mathrm{MPa}$ ), whereas the compressive strength $\left(f_{\mathrm{c}}^{\prime}\right)$ of the concrete specimens with rough construction joints ranged between $12 \mathrm{MPa}$ and $100 \mathrm{MPa}$. The clamping stress induced by the transverse reinforcement, which can be expressed as $\rho_{\mathrm{vf}} f_{\mathrm{y}}$, varied between $1.51 \mathrm{MPa}$ and 6.37 MPa for smooth construction joints and between 1.40 $\mathrm{MPa}$ and $12.29 \mathrm{MPa}$ for rough construction joints, where $\rho_{\mathrm{vf}}$ and $f_{\mathrm{y}}$ are the ratio and yield strength of the transverse reinforcement, respectively. The inclination $\left(\theta_{s}\right)$ of the transverse reinforcement to the interfacial plane varied between $45^{\circ}$ and $90^{\circ}$. Most specimens with rough construction joints were tested with no normal stresses $\left(\sigma_{x}\right)$ externally applied to the interface. Six rough construction joints were tested under additional applied tensile stresses ranging between $-0.04 f_{c}^{\prime}$ and $-0.1 f_{c}^{\prime}$. For the smooth construction joints subjected to an additional normal compressive stress, $\sigma_{x} / f_{c}^{\prime}$ was fixed at 0.15 . Compressive and tensile stresses are denoted by the symbols (+) and (-), respectively. 


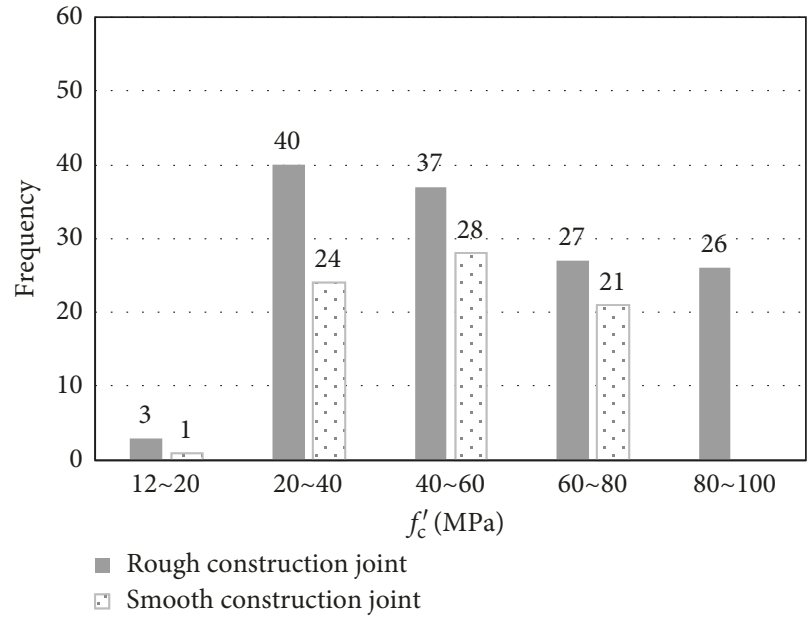

(a)

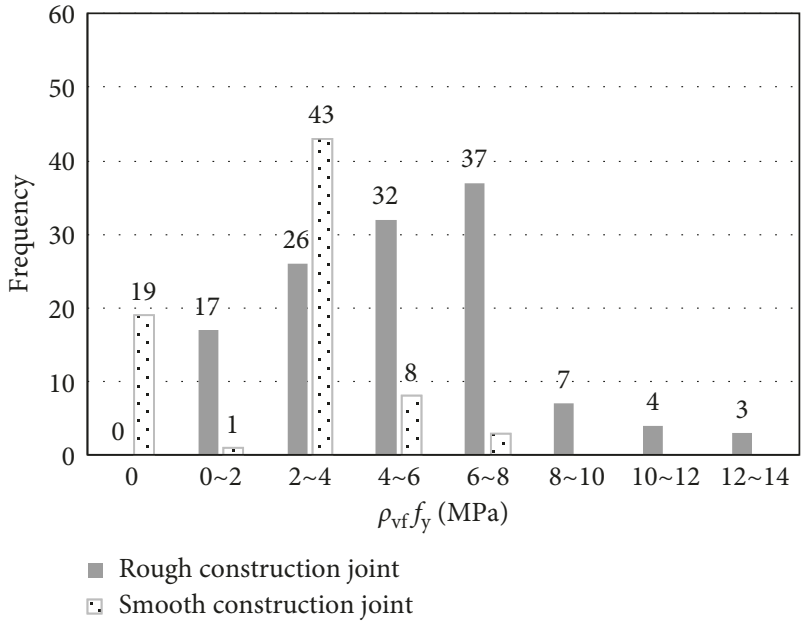

(b)

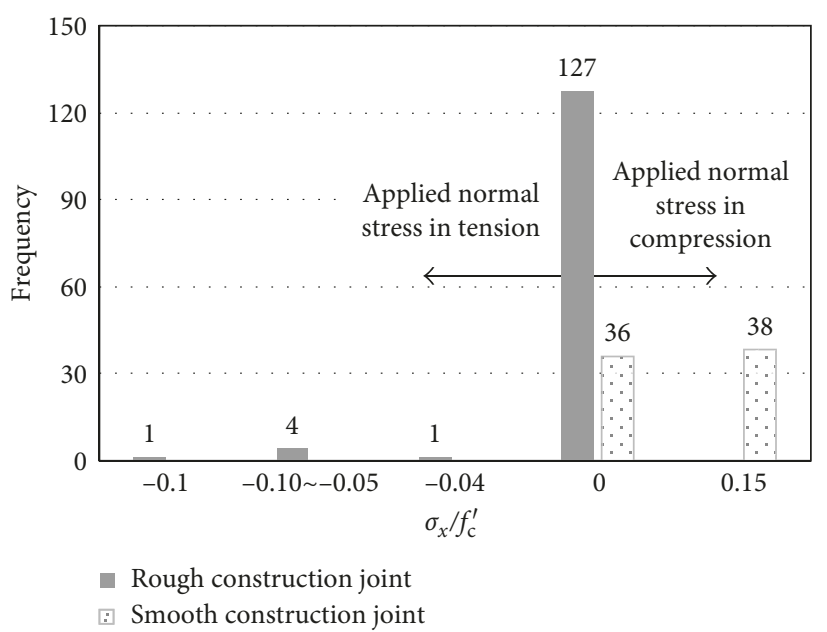

(c)

FIGURE 1: Distribution of different parameters in the 207 push-off specimens with construction joints: (a) compressive strength of concrete $\left(f_{\mathrm{c}}^{\prime}\right)$; (b) clamping stress provided by transverse reinforcement $\left(\rho_{\mathrm{vf}} f_{\mathrm{y}}\right) ;(\mathrm{c})$ ratio of applied normal stresses $\left(\sigma_{x}\right)$ to $f_{\mathrm{c}}^{\prime}$.

\section{Shear Friction Strength Models}

Most empirical equations $[4,5,10-13]$ for shear friction strength were fitted to a monolithic interface. Mattock [15] derived an experimental constant to determine the shear transfer of concrete in his empirical shear friction model for a monolithic normal-weight concrete interface. This constant was $0.1 f_{c}^{\prime}$. However, the constant was fixed at 2.76 MPa for a rough construction joint. No fitting data or explanation for smooth construction joints is available in the empirical model developed by Mattock. Therefore, this examination of the shear friction design for construction joints focuses on the code equations and mechanical models.

3.1. ACI 318-14 Equation. The ACI 318-14 [6] provision specifies that the shear friction strength $\left(\tau_{n}=V_{n} / A_{c}\right)$ of normal-weight concrete interfaces, based on the shear friction theory, is

$$
\begin{aligned}
& \tau_{n}=\frac{V_{n}}{A_{\mathrm{c}}}=\rho_{\mathrm{vf}} f_{\mathrm{y}}\left(\mu \sin \theta_{\mathrm{s}}+\cos \theta_{\mathrm{s}}\right), \\
& \tau_{n} \leq \min \left(0.2 f_{\mathrm{c}}^{\prime}, 3.3+0.08 f_{\mathrm{c}}^{\prime}, 11\right) \text { (in MPa) } \\
& \text { for rough construction joints, }
\end{aligned}
$$

$$
\tau_{n} \leq \min \left(0.2 f_{c}^{\prime}, 5.5\right)(\text { in } \mathrm{MPa})
$$

for smooth construction joints,

where $V_{n}$ is the shear friction capacity, $A_{c}$ is the section area of the interfacial plane, $\mu=\left(\tan \phi^{\prime}\right)$ is the coefficient of friction, and $\phi^{\prime}$ is the friction angle of the concrete along the construction joint. The value of $f_{y}$ is limited to $420 \mathrm{MPa}$ to avoid the overestimation of the shear transfer capacity for overreinforcement or high-strength steel reinforcement. An upper limit for $\tau_{n}$ is imposed as a function of the concrete shear resistance, although the shear transfer capacity of concrete is ignored in calculating the shear friction strength of the interfacial plane. The increase in the shear friction 
TABle 1: Comparison of cohesion and frictional coefficients of concrete in each model.

\begin{tabular}{lccccc}
\hline Model & & Cohesion & & \multicolumn{2}{c}{ Coefficient of friction } \\
& Rough joint & & Smooth joint & Rough joint & Smooth joint \\
\hline ACI 318-14 & & Ignored & & 1.0 & 0.6 \\
AASHTO & $1.66 \mathrm{MPa}$ & $0.102 \mathrm{MPa}$ & 0.0 & 0.6 \\
fib 2010 & $\left.0.1 f_{c}^{\prime}\right)^{1 / 3}$ & 0 & 0.7 & 0.6 \\
This study & $0.27\left(f_{c}^{\prime}\right)^{0.65}$ & & $0.11\left(f_{c}^{\prime}\right)^{0.65}$ & 0.95 & 0.64 \\
\hline
\end{tabular}

resistance due to the applied compressive stresses is not considered in (1), whereas the applied tensile stresses require an additional transverse reinforcement at the interfacial plane. The amount of transverse reinforcement can be determined by the equilibrium condition of force. The value of $\mu$ was set to be 1.0 and 0.6 for rough and smooth construction joints, respectively, as listed in Table 1. For the smooth construction joints, a reduced shear friction was accepted under the assumption that the shear force is primarily resisted by the dowel action of the transverse reinforcement. According to $((2 \mathrm{a})$ and $(2 \mathrm{~b}))$, the upper limit $\left[\left(\tau_{n}\right)_{\max }\right]$ is governed by $0.2 f_{\mathrm{c}}^{\prime}$ when $f_{\mathrm{c}}^{\prime}$ is less than $28 \mathrm{MPa}$, regardless of concrete joint type, whereas it is governed by $\left(3.3+0.08 f_{c}^{\prime}\right)$ for the rough construction joints and $5.5 \mathrm{MPa}$ for the smooth construction joints when $f_{\mathrm{c}}^{\prime}$ is between $28 \mathrm{MPa}$ and $100 \mathrm{MPa}$. Moreover, (1) and ((2a) and (2b)) imply that the clamping force induced by the transverse reinforcement becomes insignificant when $\rho_{\mathrm{vf}} f_{\mathrm{y}}$ exceeds a certain limit. For example, for interfaces made using concrete with $f_{\mathrm{c}}^{\prime}$ ranging between $28 \mathrm{MPa}$ and $100 \mathrm{MPa}$, the ratio of the reinforcement arranged perpendicular to the interfacial plane does not have to be greater than $\left(3.3+0.08 f_{c}^{\prime}\right) / f_{y}$ for rough construction joints and 5.5/0.6 $f_{\mathrm{y}}$ for smooth construction joints. This also implies that the ultimate frictional resistance provided by the transverse reinforcement depends on the roughness of the interfacial shear plane.

3.2. AASHTO Equation. The AASHTO equations [7] assume that interface shear resistance is directly proportional to the net normal clamping stress, based on a modified shear friction model that accounts for a contribution from cohesion and/or aggregate interlock. The AASHTO provision specifies the nominal $\tau_{n}$ of the interfacial plane as follows:

$$
\begin{aligned}
& \tau_{n}=c^{\prime}+\mu\left(\rho_{\mathrm{vf}} f_{\mathrm{y}}+\sigma_{x}\right)=c^{\prime}+\mu \sigma_{\mathrm{eq}}, \\
& \tau_{n} \leq \min \left(K_{1} f_{\mathrm{c}}^{\prime}, K_{2}\right),
\end{aligned}
$$

where $c^{\prime}$ is the concrete cohesion along the construction joint, for which the values are taken to be $0.52 \mathrm{MPa}$ and $1.66 \mathrm{MPa}$ for smooth and rough construction joints, respectively. The compressive stresses at the interfaces that develop from the transverse reinforcement and the externally applied normal compressive stresses are commonly equivalent to the summation of $\rho_{\mathrm{vf}} f_{\mathrm{y}}+\sigma_{x}$, which is then defined as the equivalent normal stress ( $\sigma_{\text {eq }}$, in MPa) [27]. The experimental constants at the upper limits of $\tau_{n}, K_{1}$ and $K_{2}$, are taken as 0.2 and $5.52 \mathrm{MPa}$, respectively, for smooth construction joints and 0.25 and $10.35 \mathrm{MPa}$, respectively, for rough construction joints. For smooth construction joints, the value of $\left(\tau_{n}\right)_{\max }$ specified in the AASHTO provision is identical to that in the ACI 318-14 equation. For rough construction joints, $\left(\tau_{n}\right)_{\max }$ is governed by $0.25 f_{\mathrm{c}}^{\prime}$ when $f_{\mathrm{c}}^{\prime}$ is less than $40 \mathrm{MPa}$, beyond which the upper limit increases to 10.35 MPa. This indicates that the AASHTO equation allows for a higher upper limit than the ACI 318-14 equation. The restriction for $f_{\mathrm{y}}$ is identical to ACI 318-14. All transverse reinforcing bars are assumed to be arranged perpendicular to the interface.

3.3. fib 2010 Equation. The fib 2010 model [14] has a similar structure to the AASHTO equation, but it considers interaction factor and dowel action of the transverse reinforcement. It is presented as follows:

$$
\begin{aligned}
\tau_{n}= & c_{1}\left(f_{\mathrm{c}}^{\prime}\right)^{1 / 3}+k_{1} \rho_{\mathrm{vf}} f_{\mathrm{yd}}\left(\mu \sin \theta_{\mathrm{s}}+\cos \theta_{\mathrm{s}}\right)+\mu \sigma_{x} \\
& +k_{2} \rho_{\mathrm{vf}} \sqrt{f_{\mathrm{yd}} f_{\mathrm{cd}}}, \\
\tau_{n} \leq & \beta_{\mathrm{c}} \nu f_{\mathrm{cd}}, \\
\nu= & 0.55\left(\frac{30}{f_{\mathrm{c}}^{\prime}}\right)^{1 / 3}<0.55,
\end{aligned}
$$

where $c_{1}$ is the factor to account for the aggregate interlock effect in concrete cohesion, $k_{1}$ and $k_{2}$ are the interaction factors for tensile force and flexural resistance generated in the transverse reinforcement, $f_{\mathrm{cd}}\left(=f^{\prime} / 1.5\right)$ and $f_{\mathrm{yd}}\left(=f_{\mathrm{y}} / 1.15\right)$ are the design compressive strength of concrete and design yield strength of reinforcement, $\beta_{\mathrm{c}}$ is the factor for the strength of the compression strut, and $v$ is the strength reduction factor of concrete. The values of $c_{1}, k_{1}, k_{2}$, and $\beta_{\mathrm{c}}$ are taken to be $0,0.5,1.1$, and 0.4 , respectively, for smooth construction joints. The corresponding values for rough construction joints are $0.1,0.5,0.9$, and 0.5 , respectively.

The fib 2010 considers that the main contributions to the sear resistance along the construction joints result from mechanical interlocking and adhesive bonding of concrete, friction due to external compression forces normal to the interface and clamping forces by reinforcement, and dowel action of reinforcement crossing the interface. The interlocking and adhesive bonding capacities of concrete depend on the surface roughness of the construction joints, assuming that the interlock effects at smooth construction joints are negligible. Compared with the cohesion capacity of the AASHTO equation, (4) yields a lower value, indicating that the interlocking and adhesive bonding capacities of concrete disappear compared to the other mechanisms of 
shear friction and dowel action. The upper limit of $\tau_{n}$ increases linearly with respect to $f_{c}^{\prime}$. For example, the upper limit of $\tau_{n}$ for construction joints is calculated to be $3.67 \mathrm{MPa}$ when $f_{\mathrm{c}}^{\prime}$ is $20 \mathrm{MPa}$ and $12.3 \mathrm{MPa}$ when $f_{\mathrm{c}}^{\prime}$ is $100 \mathrm{MPa}$. Compared with the value of $\mu$ in the ACI 318-14 and AASHTO provisions, the fib 2010 specifies the same value for smooth surfaces but a 30\% lower value for rough surfaces, as listed in Table 1.

\subsection{Mechanical Equations Derived Using Concrete Plasticity.} Nielsen and Hoang [28] and Kwon et al. [8] showed that mechanism analysis based on the upper-bound theorem of concrete plasticity is a very promising method for describing the concrete cohesion and shear friction response of concrete monolithic interfaces or construction joints. They reported that concrete interfaces under direct shear and axial loads are usually separated into two rigid blocks at failure, as shown in Figure 2. One rigid block has two translational and rotational displacement components relative to the other rigid block. Thus, one rigid block can be assumed to rotate about an instantaneous center (IC). Similar to the failure mechanism of monolithic interfaces, the shear plane at failure along a construction joint can be regarded as a plane strain problem. Nielsen and Hoang [28] demonstrated that the angle between the relative displacement $(\delta)$ about an IC and the failure plane can be assumed to be equal to the frictional angle $\left(\phi^{\prime}\right)$ of concrete along construction joint. This angle can also be considered to be a constant value. Furthermore, tensile resistance in the concrete at construction joints is not usually expected, implying that the shear transfer of concrete along construction joints is entirely resisted by concrete cohesion. Concrete is regarded as a rigid perfectly plastic material that obeys a modified Coulomb failure criteria with effective compressive and tensile strengths. Therefore, if the tensile strength of concrete is ignored, the integrated model [8] for the shear friction strength of monolithic concrete interfaces can be modified for construction joints in the following form:

$$
\tau_{n}=c^{\prime}+\rho_{\mathrm{vf}} f_{\mathrm{y}} \frac{\cos \left(\theta_{\mathrm{s}}-\phi^{\prime}\right)}{\cos \phi^{\prime}}+\sigma_{x} \tan \phi^{\prime} .
$$

For construction joints with transverse reinforcement of $\theta_{\mathrm{s}}=90^{\circ}$, (5) can be written as follows:

$$
\tau_{n}=c^{\prime}+\left(\rho_{\mathrm{vf}} f_{\mathrm{y}}+\sigma_{x}\right) \tan \phi^{\prime}=c^{\prime}+\sigma_{\mathrm{eq}} \tan \phi^{\prime} .
$$

Overall, the mechanical approach derived from the upper-bound theorem for the construction joints has the same format as shear friction theory. Equations (5) and (6) imply that the shear friction strength of nonreinforced construction joints without additional axial stresses is resisted only by the concrete cohesion along the interfacial failure plane. The AASHTO provision assumes the value of $c^{\prime}$ to be a constant, whereas fib 2010 [14] considers it to be a function of $f_{\mathrm{c}}^{\prime}$, as listed in Table 1. Nielsen and Hoang [28] reported that the value of $c^{\prime}$ depends on $f_{c}^{\prime}$ and the roughness along the interfacial plane. Dahl [29] conducted a regression analysis using a small set of test data obtained

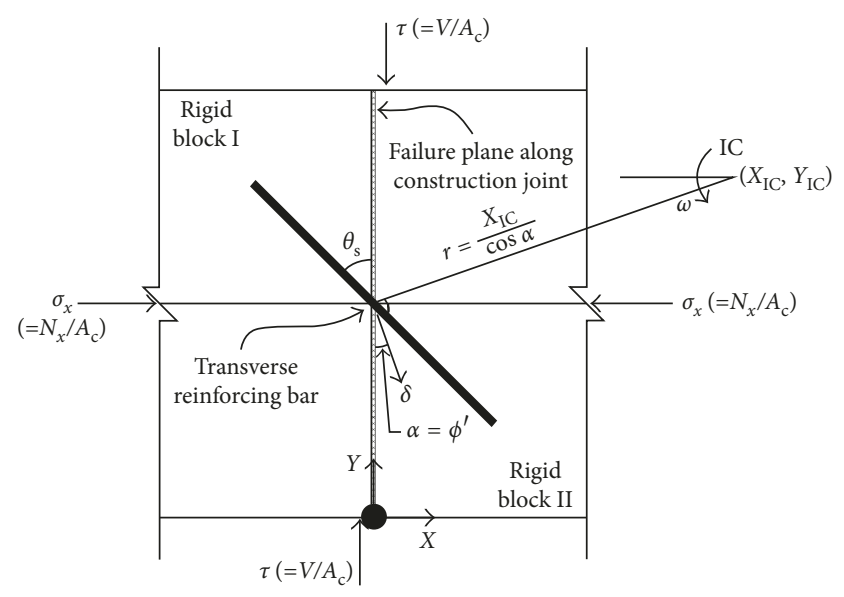

FIGURE 2: Idealized failure mechanism of the concrete interface with construction joints.

from four push-off specimens with smooth construction joints and showed that $c^{\prime}$ could be expressed as a function of $\left(f_{c}^{\prime}\right)^{0.5}$. Experimental programs for determining the value of $c^{\prime}$ of nonreinforced construction joints are very scarce. If push-off specimens analysed by Choi et al. [30] and Hwang [18] are plotted to show $c^{\prime}$ for smooth and rough construction joints as a function of $f_{c}^{\prime}$, the approximate relationship obtained is expressed as follows (Figure 3):

$$
\begin{aligned}
& c^{\prime}=0.11\left(f_{\mathrm{c}}^{\prime}\right)^{0.65} \quad \text { for smooth construction joints, } \\
& c^{\prime}=0.27\left(f_{\mathrm{c}}\right)^{0.65} \text { for rough construction joints. }
\end{aligned}
$$

According to the code provisions, the enhanced cohesion on the rough surface due to mechanical treatment is estimated to be $320 \%$ for the AASHTO equation, whereas the fib 2010 neglects the cohesion capacity of smooth surface. Equation $((7 a)$ and $(7 b))$ shows that the rough surface has approximately $245 \%$ higher cohesion than the smooth surface. These equations yield a higher value for $c^{\prime}$ than the code equations, including fib 2010, but a lower value than the calculation of Nielsen and Hoang's equation [28]. Equation ((7a) and (7b)) would need to be further verified using the test data conducted under extensive range of $f_{c}^{\prime}$ values and for construction joints with the other surface impact treatments.

To determine the value of $\phi^{\prime}$ using the test data, (5) is rearranged as follows:

$$
\phi^{\prime}=\tan ^{-1}\left(\frac{\tau_{n}-c^{\prime}-\rho_{\mathrm{vf}} f_{\mathrm{y}} \cos \theta_{\mathrm{s}}}{\rho_{\mathrm{vf}} f_{\mathrm{y}} \sin \theta_{\mathrm{s}}+\sigma_{x}}\right) .
$$

The calculated $\phi^{\prime}$ values for the test data in the database commonly range between $29.4^{\circ}$ and $44.5^{\circ}$ for smooth construction joints and between $33.3^{\circ}$ and $54.4^{\circ}$ for rough construction joints. The average value of $32.8^{\circ}(\mu=0.64)$ for smooth construction joints and $43.5^{\circ}(\mu=0.95)$ for rough construction joints are within the typical ranges specified in fib model code 2010 [14].

Figure 4 plots the relationship between $\rho_{\mathrm{vf}} f_{\mathrm{y}}$ and the normalized shear friction strength $\left(\tau_{n} / f_{\mathrm{c}}^{\prime}\right)$ for rough construction joints. The normalized shear friction strength increases in proportion to $\rho_{\mathrm{vf}} f_{\mathrm{y}}$ up to a certain limit, beyond 


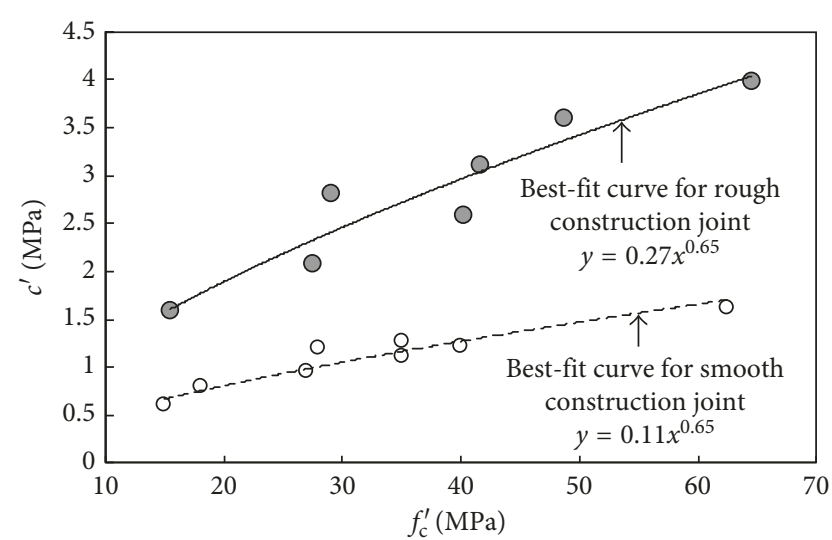

FIGURE 3: Relationship between $c^{\prime}$ and $f_{c}^{\prime}$ for the nonreinforced construction joints.

which the rate of increase gradually slows. This implies that the $\tau_{n}$ at the overreinforced construction joints is governed by the crushing of the concrete before the transverse reinforcement reaches its yield strength. Hence, $\tau_{n}$ needs to be limited to certain value in order to avoid the overestimation of the shear transfer of transverse reinforcement due to the precrushing failure of concrete. Figure 5 shows the idealized strut-and-tie action needed to transfer the applied shear along the construction joints [28] based on the concrete plasticity. The combined action of the shear force and clamping forces in the transverse reinforcement yields an inclined compressive force across the interfacial plane. The equilibrium condition of the forces yields the following relationship:

$$
\left(\tau_{n}\right)_{\max } \cdot A_{c}=v_{c} f_{2 \max } A_{c} \sin \theta \cos \theta,
$$

where $v_{c}$ is the effectiveness factor of the concrete in compression to account for the assumed rigid plasticity, $f_{2 \max }$ is the compressive strength of a cracked concrete strut under biaxial state of stresses, and $\theta\left(=(\pi / 2)-\phi^{\prime}\right)$ is the inclination of the concrete struts appearing perpendicfular to the frictional angle [31]. Kwon et al. [8] calculated the value of $v_{c}$ using the actual stress-strain curve of concrete and formulated it as follows:

$$
v_{\mathrm{c}}=0.79 \exp \left[-0.03\left(\frac{f_{\mathrm{c}}^{\prime}}{f_{\mathrm{co}}}\right)^{0.9}\left(\frac{\rho_{\mathrm{o}}}{\rho_{\mathrm{c}}}\right)^{1.6}\right]
$$

where $f_{\mathrm{co}}(=10 \mathrm{MPa})$ and $\rho_{\mathrm{o}}\left(=2300 \mathrm{~kg} / \mathrm{m}^{3}\right)$ are the reference values for the compressive strength and the unit weight of concrete, respectively. Belarbi and Hsu [32] tested concrete panels loaded under in-plane shear and proposed the following relationship between $f_{2 \max }$ and $f_{c}^{\prime}$ :

$$
f_{2 \max }=\frac{0.9}{\sqrt{1+400 \varepsilon_{1}}} f_{c}^{\prime}
$$

where $\varepsilon_{1}$ is the transverse tensile strain. For the cracked concrete along the interfacial plane, the value of $\varepsilon_{1}$ depends on the magnitude of $f_{\mathrm{c}}^{\prime}$ and $\rho_{\mathrm{vf}} f_{\mathrm{y}}$. However, it is not easy task to establish the relationship of $\varepsilon_{1}$ and the influencing parameters in the concrete interface subjected to direct shear. For simplicity of the equation for $\left(\tau_{n}\right)_{\max }$, the present study assumes that $\varepsilon_{1}$ would be approximately equivalent to the yield strain

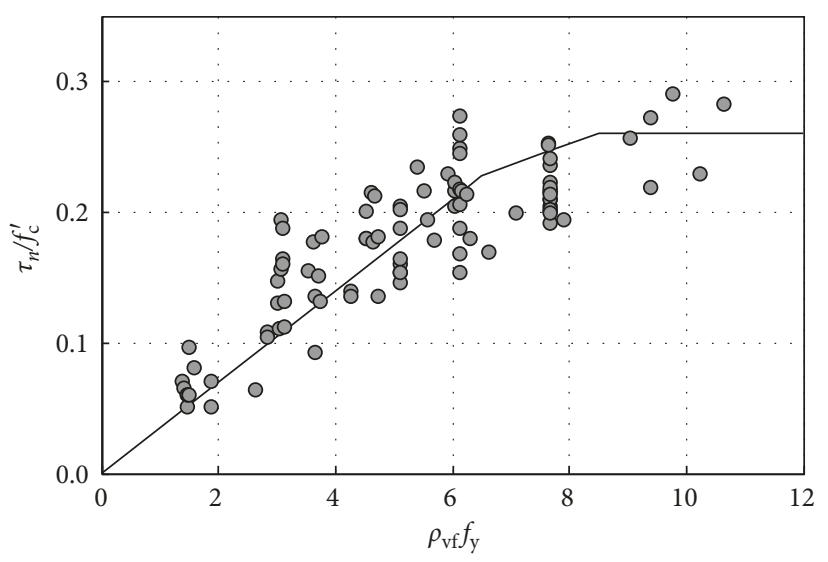

○ Rough construction joint

FIgURE 4: Relationship between $\tau_{n} / f_{\mathrm{c}}^{\prime}$ and $\rho_{\mathrm{vf}} f_{\mathrm{y}}$ for the construction joints.

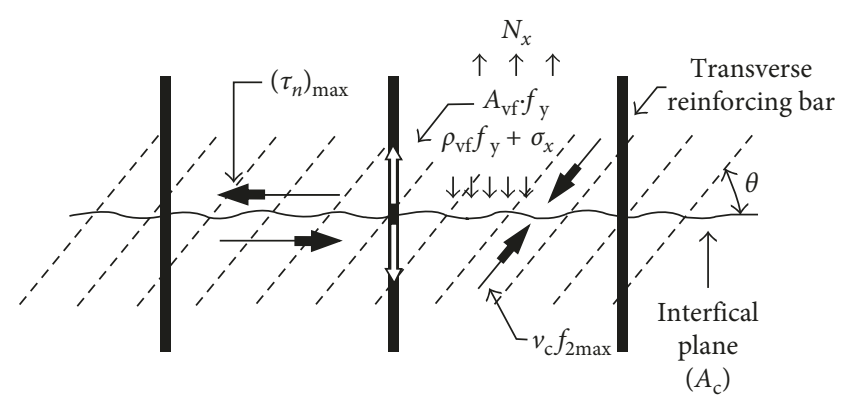

FIGURE 5: Idealized strut-and-tie action at the construction joints.

$(\approx 0.002)$ of the mild transverse reinforcement. Overall, the upper limit of the shear friction strength at the construction joints can be simply expressed as follows:

$$
\left(\tau_{n}\right)_{\max }=0.67 v_{\mathrm{c}} f_{\mathrm{c}}^{\prime} \sin \phi^{\prime} \cos \phi^{\prime} .
$$

Figure 6 shows the variation of $\left(\tau_{n}\right)_{\max } / f_{\mathrm{c}}^{\prime}$ calculated using the code and the proposed equations according to $f_{\mathrm{c}}^{\prime}$. All the equations yield the same trend, that is, $\left(\tau_{n}\right)_{\max } / f_{\mathrm{c}}^{\prime}$ decreases with the increase of $f_{c}^{\prime}$, implying that the increasing rate of the crushing strength of concrete under a biaxial stress state is not linearly proportional to $f_{c}^{\prime}$. Rahal [33] empirically proposed the upper limit based on experimental results using normal- and high-strength concrete, indicating that $\left(\tau_{n}\right)_{\max } / f_{\mathrm{c}}^{\prime}$ varies linearly from 0.31 to 0.22 when $f_{c}^{\prime}$ increases from $20 \mathrm{MPa}$ to $100 \mathrm{MPa}$, regardless of the roughness of the concrete substrate along the interface. For smooth construction joints (Figure 6(a)), the ACI 318-14 and AASHTO equations have the same values of $\left(\tau_{n}\right)_{\max } / f_{c}^{\prime}$, producing lower values than rough construction joints when $f_{c}^{\prime}$ is greater than $28 \mathrm{MPa}$. That is, a higher rate of decrease in $\left(\tau_{n}\right)_{\max } / f_{\mathrm{c}}^{\prime}$ is observed in the smooth construction joints than in the rough construction joints. The developed equation has higher $\left(\tau_{n}\right)_{\max } / f_{\mathrm{c}}^{\prime}$ values than the AASHTO and fib 2010 equations. For rough construction joints (Figure 6(b)), the ACI 318-14 equation exhibits a lower $\left(\tau_{n}\right)_{\max }$ than the other equations when $f_{\mathrm{c}}^{\prime}$ is lower than 


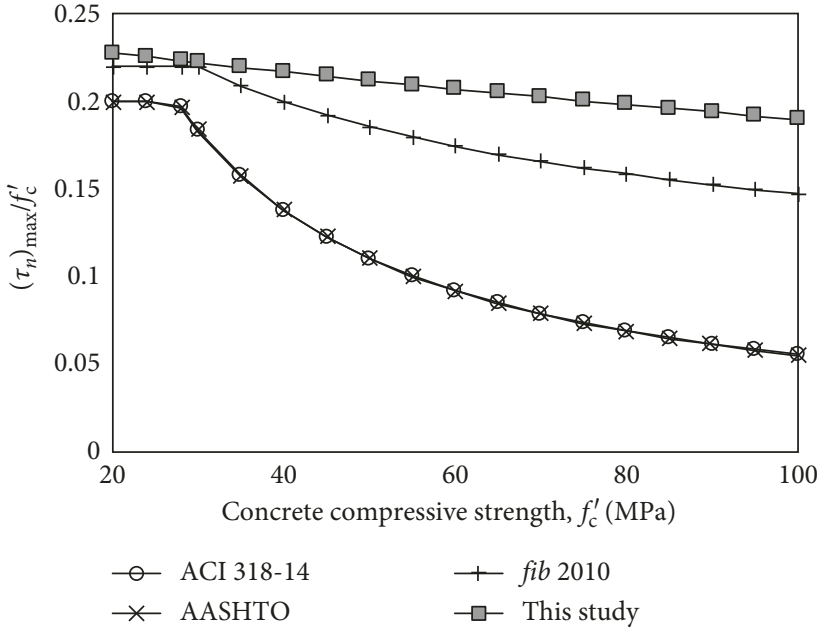

(a)

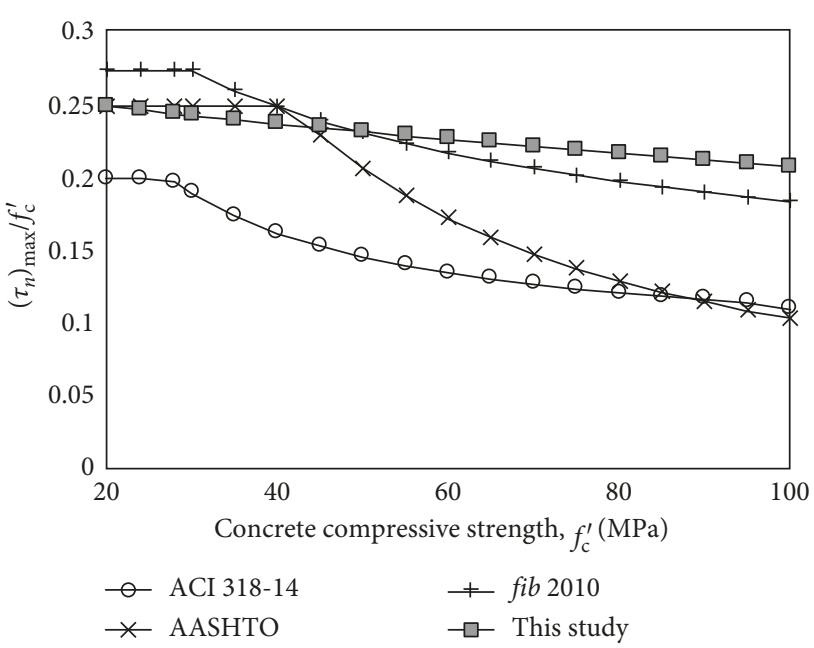

(b)

FIGURE 6: Comparisons of $\left(\tau_{n}\right)_{\max }$ in the code and proposed models: (a) smooth construction joints; (b) rough construction joints.

$90 \mathrm{MPa}$. The value of $\left(\tau_{n}\right)_{\max } / f_{\mathrm{c}}^{\prime}$ calculated using the AASHTO equation remains constant at 0.25 up to an $f_{c}^{\prime}$ of $50 \mathrm{MPa}$, beyond which the value decreases rapidly. The value of $\left(\tau_{n}\right)_{\max } / f_{\mathrm{c}}^{\prime}$ calculated using the fib 2010 equation also shows similar trend to the AASHTO equation but yields higher level than the other models when $f_{c}^{\prime}$ is less than $40 \mathrm{MPa}$. The developed equation has a higher $\left(\tau_{n}\right)_{\max } / f_{\mathrm{c}}^{\prime}$ value for rough construction joints than for smooth construction joints, resulting in lower values than the fib 2010 equation when $f_{\mathrm{c}}^{\prime}$ is lower than $50 \mathrm{MPa}$.

\section{Comparison of Prediction Models and Test Results}

4.1. Statistical Comparisons. Figure 7 shows comparisons between the measured shear friction strength of the push-off specimens with construction joints in the database and the predictions made by the code and developed equations. Note that any strength reduction factors are not considered in calculating shear friction strength using code equations and proposed model. Table 2 lists the statistical values for the mean $\left(\gamma_{\mathrm{m}}\right)$, standard deviation $\left(\gamma_{\mathrm{s}}\right)$, and coefficient of variation $\left(\gamma_{\mathrm{v}}\right)$ of the ratios $\left[\gamma=\left(\tau_{n}\right)_{\text {Exp. }} /\left(\tau_{n}\right)_{\text {Pre. }}\right]$ between the experimental and predicted shear friction strengths. If $\gamma>1$, the prediction model is conservative. Considering that various sources of test data may have different geometrical dimensions, material properties, and test arrangements, the $5 \%\left(\gamma_{5 \%}\right)$ and $95 \%\left(\gamma_{95 \%}\right)$ fractiles in all the tests are employed for evaluating the reliability of the prediction equations. The 5\% and $95 \%$ fractiles are calculated from statistics as follows [34]:

$$
\begin{aligned}
\gamma_{5 \%} & =\gamma_{\mathrm{m}}-R_{0} \gamma_{\mathrm{s}}, \\
\gamma_{95 \%} & =\gamma_{\mathrm{m}}+R_{0} \gamma_{\mathrm{s}} .
\end{aligned}
$$

The coefficient, $R_{0}$, depends on the number $(n)$ of test data samples used to compute the average and standard deviation. Because the values of $R_{0}$ range from 1.645 for $n$ more than 120 , to 2.010 for $n$ of 40 , and to 2.568 for $n$ of 10 ,
$R_{0}$ can be calculated from the interpolation of these values. The specimens without transverse reinforcement were excluded from the comparisons made using the ACI 318-14 equation because the code equation neglects concrete cohesion. The significant findings derived from the comparisons are discussed below.

The ACI 318-14 equation (Figure 7(a)) considerably underestimates the shear friction strength of reinforced smooth construction joints, which results in very high values of $\gamma_{\mathrm{m}}$ and $\gamma_{95 \%}$. The values exceed 3.15 and 7.29 , respectively. This is because the predictions do not consider concrete shear transfer by cohesion and are governed by the upper limit of $\tau_{n}$ when $\sigma_{\mathrm{vf}} f_{\mathrm{y}}$ is greater than approximately $8.7 \mathrm{MPa}$. For rough construction joints, the ACI 318-14 equation is still very conservative, yielding a high value of $\gamma_{95 \%}$ exceeding 3.95, although a few unsafe data points are observed and $\gamma_{\mathrm{m}}$ decreases to 2.16. Large scattering of the data for the $\gamma$ value is observed in the ACI 318-14 equations, resulting in considerably high $\gamma_{\mathrm{s}}$ values of 2.23 and 1.13 for smooth and rough construction joints, respectively. The AASHTO equation also provides underestimated results (Figure 7(b)) for smooth construction joints, although a few overestimated data points are observed when $\sigma_{\text {eq }}$ is greater than approximately $11 \mathrm{MPa}$. The values of $\gamma_{\mathrm{m}}$ and $\gamma_{\mathrm{s}}$ obtained using the AASHTO equation are far smaller than those obtained using the ACI 318-14 equation. However, large scattering of the $\gamma$ values is still observed in the AASHTO equation. Therefore, significant amounts of overestimated data points are observed for rough construction joints. The predictions obtained from the fib 2010 equation are frequently lower than the test results (Figure 7(c)), regardless of the roughness of the interfacial surface. The predictions yield lower values of $\gamma_{\mathrm{m}}$ and $\gamma_{\mathrm{s}}$ for smooth construction joints than the previous code equations. The unconservative trend of the fib 2010 equation for smooth construction joints is magnified when $\sigma_{\text {eq }}$ is greater than approximately $11 \mathrm{MPa}$. The fib 2010 equation for rough construction joints has higher $\gamma_{\mathrm{m}}$ and $\gamma_{\mathrm{s}}$ values than the AASHTO equation. The predictions of the proposed model agree more closely with the test results (Figure $7(\mathrm{~d})$ ), 


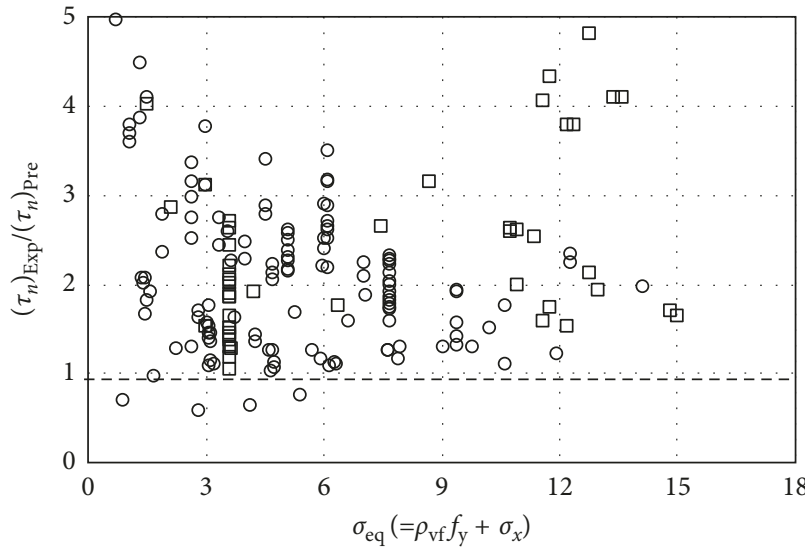

○ Rough construction joint

$\square$ Smooth construction joint

(a)

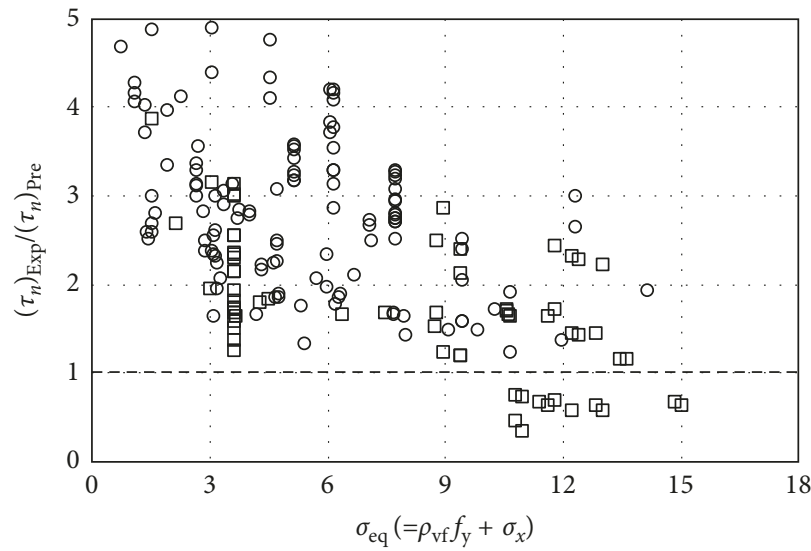

○ Rough construction joint

$\square$ Smooth construction joint

(c)

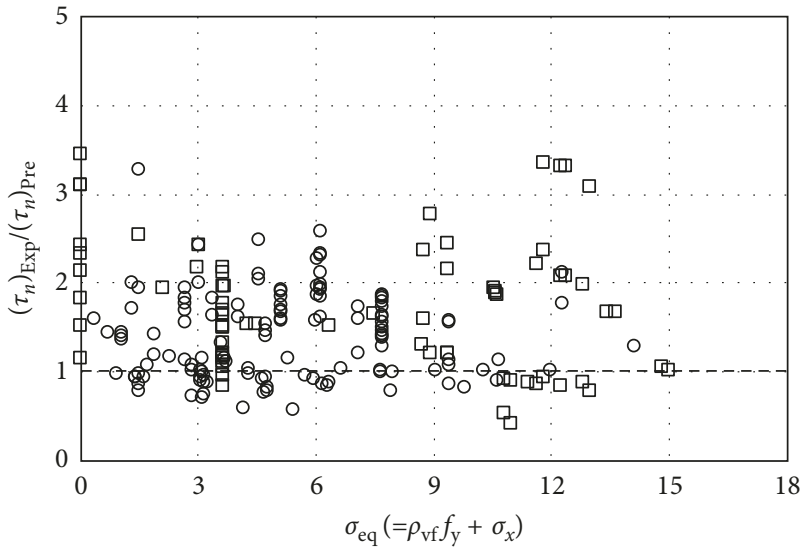

○ Rough construction joint

$\square$ Smooth construction joint

(b)

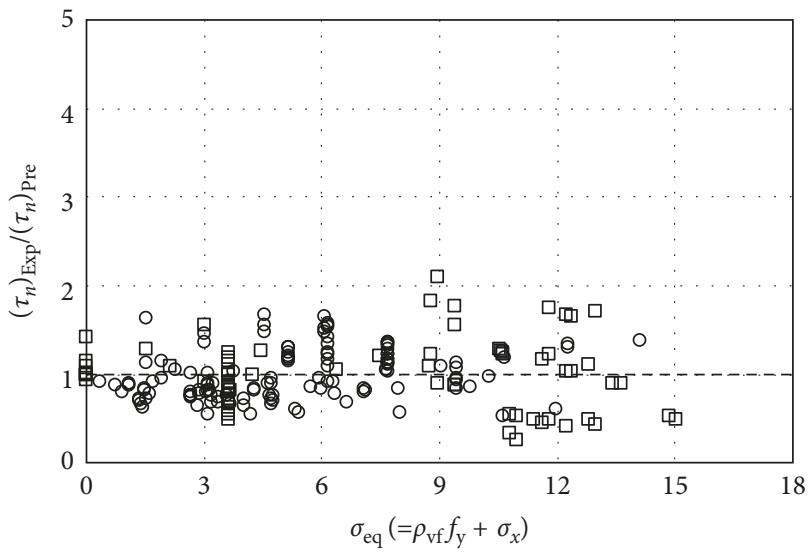

○ Rough construction joint

$\square$ Smooth construction joint

Figure 7: Comparisons of the measured and predicted shear friction strengths: (a) ACI 318-14 equation; (b) AASHTO equation; (c) fib 2010 equation; (d) this study.

TABLE 2: Statistical comparison of measured and predicted shear friction strengths.

\begin{tabular}{|c|c|c|c|c|c|}
\hline \multirow{2}{*}{ Interface type } & \multirow{2}{*}{ Statistical value } & \multicolumn{4}{|c|}{ Proposer } \\
\hline & & ACI $318-14$ & AASHTO & fib 2010 & This study \\
\hline \multirow{5}{*}{ Smooth construction joint } & $\gamma_{\mathrm{m}}$ & 3.15 & 1.80 & 1.73 & 0.99 \\
\hline & $\gamma_{\mathrm{s}}$ & 2.23 & 0.87 & 0.76 & 0.39 \\
\hline & $\gamma_{\mathrm{v}}$ & 0.71 & 0.48 & 0.44 & 0.39 \\
\hline & $\gamma_{5 \%}$ & NA & 0.18 & 0.31 & 0.27 \\
\hline & $\gamma_{95 \%}$ & 7.29 & 3.42 & 3.14 & 1.72 \\
\hline \multirow{5}{*}{ Rough construction joint } & $\gamma_{\mathrm{m}}$ & 2.16 & 1.41 & 2.99 & 1.00 \\
\hline & $\gamma_{\mathrm{s}}$ & 1.13 & 0.49 & 1.35 & 0.28 \\
\hline & $\gamma_{\mathrm{v}}$ & 0.52 & 0.35 & 0.45 & 0.28 \\
\hline & $\gamma_{5 \%}$ & 0.36 & 0.63 & 0.84 & 0.55 \\
\hline & $\gamma_{95 \%}$ & 3.95 & 2.20 & 5.14 & 1.44 \\
\hline \multirow{5}{*}{ Total } & $\gamma_{\mathrm{m}}$ & 2.46 & 1.56 & 2.56 & 1.01 \\
\hline & $\gamma_{\mathrm{s}}$ & 1.64 & 0.68 & 1.33 & 0.32 \\
\hline & $\gamma_{\mathrm{v}}$ & 0.67 & 0.44 & 0.52 & 0.32 \\
\hline & $\gamma_{5 \%}$ & NA & 0.43 & 0.38 & 0.48 \\
\hline & $\gamma_{95 \%}$ & 5.15 & 2.68 & 4.75 & 1.55 \\
\hline
\end{tabular}




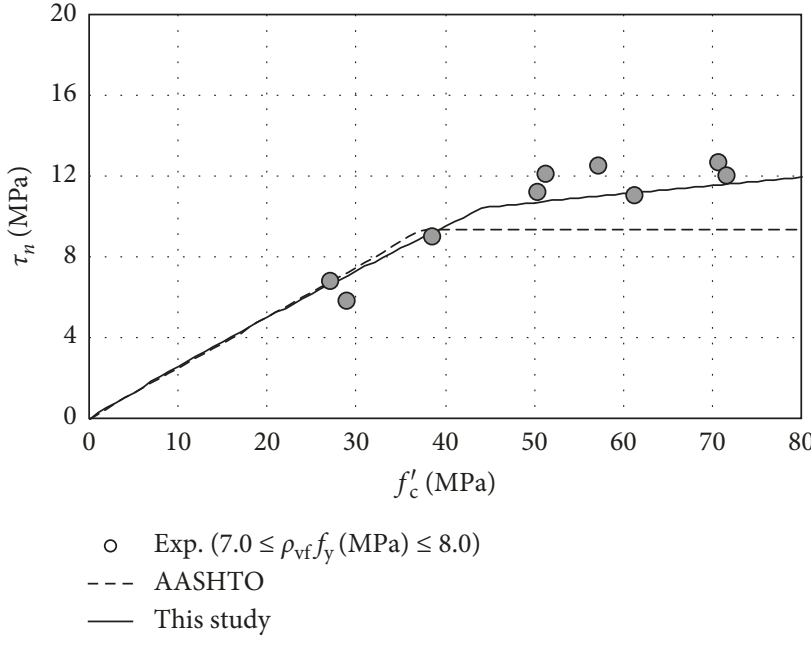

(a)

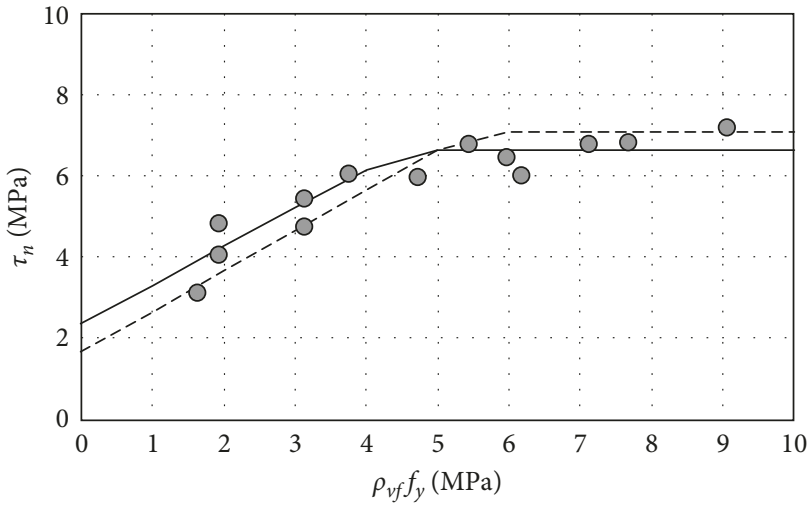

○ $\quad$ Exp. $\left(25 \leq f_{\mathrm{c}}^{\prime}(\mathrm{MPa}) \leq 30\right)$

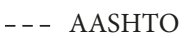

— This study

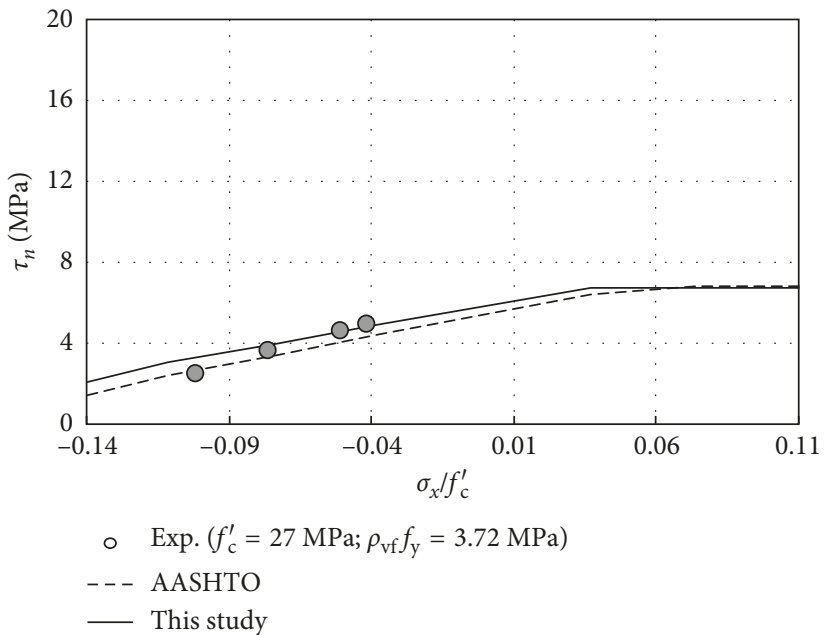

(c)

FIGURE 8: Effects of different parameters on the shear friction strength of construction joints: (a) compressive strength of concrete $\left(f_{\mathrm{c}}^{\prime}\right)$; (b) clamping stress provided by transverse reinforcement $\left(\rho_{\mathrm{vf}} f_{\mathrm{y}}\right)$; (c) ratio of applied normal stresses $\left(\sigma_{x}\right)$ to $f_{\mathrm{c}}^{\prime}$.

exhibiting the lowest scatter value of $\gamma$ according to the variation of $\rho_{\text {eq }}$. The values for $\gamma_{\mathrm{m}}$ and $\gamma_{\mathrm{s}}$ are 0.99 and 0.39 , respectively, for smooth construction joints and 1.00 and 0.28 , respectively, for rough construction joints. The overall values of $\gamma_{\mathrm{m}}, \gamma_{\mathrm{s}}$, and $\gamma_{\mathrm{v}}$ for the complete dataset are 1.01, 0.32, and 0.32 , respectively, indicating smaller deviation in the proposed model than in the code equations when the shear friction strength of construction joints is predicted. Meanwhile, the proposed model exhibits more unconservative results than code equations, especially for construction joints with $\sigma_{\text {eq }}$ exceeding $11 \mathrm{MPa}$. Thus, the proposed model needs to be further adjusted to incorporate the strength reduction factor considering the values of $\gamma_{95 \%}$ and $\gamma_{5 \%}$ to reduce the unconservative estimation of shear friction strength.

4.2. Verification of Primary Influencing Parameters. The influence of the primary parameters on the shear friction strength of the rough construction joints is studied using the proposed model and the AASHTO equation, as well as appropriate experimental results available in the database. To examine whether the code provisions reasonably consider the influencing parameters, the AASHTO equation with lower $\gamma_{\mathrm{s}}$ and $\gamma_{\mathrm{v}}$ values than the ACI 318-14 and fib 2010 equations is selected. In the parametric study, one parameter is incrementally changed while the others are kept constant. However, because the test results in the database were collected from different sources, it would not be possible to strictly achieve this, so average values of the concrete and steel reinforcement properties are used.

Figure 8(a) shows the effect of $f_{c}^{\prime}$ on $\tau_{n}$ for rough construction joints without additionally applied normal stresses. The prediction obtained using the AASHTO equation increases in proportion to $f_{\mathrm{c}}^{\prime}$ up to a certain limit, beyond which it remains constant. The AASHTO equation tends to underestimate the shear friction strength of rough construction joints for $f_{\mathrm{c}}^{\prime}>50 \mathrm{MPa}$. The proposed model shows a similar trend to the AASHTO equation, yet it has 
a higher threshold point. The threshold point of $\tau_{n}$ against $f_{\mathrm{c}}^{\prime}$ varies according to $\sigma_{\text {eq }}$. The predictions of the proposed model exhibit a good correlation with the test results.

A similar trend for the effect of $\rho_{\mathrm{vf}} f_{\mathrm{y}}$ on $\tau_{n}$ for rough construction joints is observed in both equations (Figure 8(b)), indicating a bilinear relationship with a threshold point at a certain $\rho_{\mathrm{vf}} f_{\mathrm{y}}$. This trend is also verified by the test data. The proposed model exhibits slightly better accuracy than the AASHTO equation with respect to the experimental data, with $\rho_{\mathrm{vf}} f_{\mathrm{y}}$ exceeding approximately $6 \mathrm{MPa}$.

The effect of $\sigma_{x} / f_{c}^{\prime}$ on $\tau_{n}$ for rough construction joints with $f_{\mathrm{c}}^{\prime}$ of $27 \mathrm{MPa}$ and $\rho_{\mathrm{vf}} f_{\mathrm{y}}$ of $3.72 \mathrm{MPa}$ is shown in Figure $8(\mathrm{c})$. There are no available data for rough construction joints subjected to an externally applied normal stress in compression, as shown in Figure 1. Both equations exhibit a very close relationship between $\sigma_{x} / f_{c}^{\prime}$ and $\tau_{n}$, indicating that a further increase in $\tau_{n}$ is not expected when $\sigma_{x} / f_{c}^{\prime}$ is greater than a certain value. For the rough construction joints subjected to an additional tensile stress, the predictions obtained using both equations agree well with the test results.

\section{Conclusions}

This study develops rational approach and model for shear friction design of concrete interface with smooth and rough construction joints on the basis of the upper-bound theorem of concrete plasticity. The reliability and limitations of code equations and proposed models for determining the shear friction strength $\left(\tau_{n}\right)$ of construction joints are examined through comparisons with test data compiled from 207 push-off specimens with interfaces between concrete that was cast at different times. However, this study classified the surface roughness into two categories of smooth and rough construction joints. Hence, the code and proposed equations need to be further verified for construction joints treated with other impact methods. The effects of various parameters on the shear friction strength of construction joints are also investigated using test results and prediction models, including the AASHTO equation and a proposed one. The following conclusions may be drawn according to the results obtained using the code equations and the proposed model:

(1) The developed equation has a higher upper limit for $\tau_{n}$ than the other equations but yields a lower upper limit for rough construction joints than the fib 2010 equation for $f_{c}^{\prime}<50 \mathrm{MPa}$. The ACI 318-14 equation gives a lower upper limit for $\tau_{n}$ for rough construction joints than the other equations when $f_{c}^{\prime}$ is lower than $90 \mathrm{MPa}$.

(2) The ACI 318-14 equation significantly underestimates the shear friction strength of reinforced construction joints. In addition, larger scattering of the $\gamma$ value is obtained with the ACI 318-14 equation than with the other equations, resulting in very high standard deviation $\left(\gamma_{\mathrm{s}}\right)$ values of 2.23 and 1.13 for the ratios $(\gamma)$ in the cases of smooth and rough construction joints, respectively.
(3) Large scattering of the $\gamma$ value is also observed in the AASHTO equation, although the determined values of the mean $\left(\gamma_{\mathrm{m}}\right)$ and $\gamma_{s}$ are considerably lower than those obtained using the ACI 318-14 equation.

(4) The predictions obtained using the fib 2010 equation frequently underestimate the test results, regardless of the roughness of the interfacial surface. The predictions yield lower values of $\gamma_{\mathrm{m}}$ and $\gamma_{\mathrm{s}}$ for smooth construction joints than the previous code equations. The unconservative trend of the fib 2010 equation for smooth construction joints is magnified when $\sigma_{\mathrm{eq}}$ is greater than approximately $11 \mathrm{MPa}$.

(5) The predictions of the proposed model agree well with the test results, indicating the lowest scatter value for $\gamma$. The values of $\gamma_{\mathrm{m}}$ and $\gamma_{\mathrm{s}}$ are 0.99 and 0.39 , respectively, for smooth construction joints and 1.00 and 0.28 , respectively, for rough construction joints. This results in overall values for $\gamma_{\mathrm{m}}$ and $\gamma_{\mathrm{s}}$ of 1.01 and 0.32 , respectively, for the complete dataset.

(6) According to the proposed model, the values of the cohesion and coefficient of friction of concrete are determined as $0.11\left(f_{c}^{\prime}\right)^{0.65}$ and 0.64 , respectively, for smooth construction joints and $0.27\left(f_{c}^{\prime}\right)^{0.65}$ and 0.95 , respectively, for rough construction joints.

\section{Notation}

$A_{\mathrm{c}}: \quad$ Section area of interfacial failure plane

$A_{\mathrm{vf}}$ : $\quad$ Area of transverse reinforcement crossing

interfacial failure plane

$c^{\prime}$ : $\quad$ Cohesion of concrete along construction joints

$c_{1}$ : Factor to account for roughness of interfacial plane in concrete cohesion

$f_{2 \max }$ : Compressive strength of cracked concrete under biaxial stress

$f_{\mathrm{c}}^{\prime}: \quad$ Compressive strength of concrete

$f_{\text {co }}$ : $\quad$ Reference value of the compressive strength of concrete $(=10 \mathrm{MPa})$

$f_{\text {te }}: \quad 5 \%$ fractile for tensile strength of concrete

$f_{\mathrm{y}}$ : Yield strength of transverse reinforcement

$f_{\mathrm{cd}}$ : Design compressive strength of concrete

$f_{\text {yd }}$ : Design tensile strength of reinforcement

$k_{1}$ : Interaction factors for tensile force activated in the reinforcement or the dowels

$k_{2}$ : $\quad$ Interaction factors for flexural resistance activated in the reinforcement or the dowels

$n$ : $\quad$ Number of test data

$V_{n}$ : $\quad$ Direct shear force at interfacial failure plane

$\beta_{c}$ : $\quad$ Factor for the strength of the compression strut

$\gamma: \quad$ Ratio between test results and predictions

$\gamma_{5 \%}: \quad 5 \%$ fractile of $\gamma$ values

$\gamma_{95 \%}: \quad 95 \%$ fractile of $\gamma$ values

$\gamma_{\mathrm{m}}: \quad$ Mean of $\gamma$ values

$\gamma_{\mathrm{s}}: \quad$ Standard deviation of $\gamma$ values

$\gamma_{\mathrm{v}}$ : Coefficient of variation of $\gamma$ values

$\delta$ : $\quad$ Relative displacement about an instantaneous center

$\varepsilon_{1}$ : Transverse tensile strain along interfacial plane 
$\theta: \quad$ Inclination of concrete strut relative to interfacial failure plane

$\theta_{\mathrm{s}}: \quad$ Inclination of transverse reinforcement relative to interfacial failure plane

$\mu: \quad$ Coefficient of friction

$v: \quad$ Strength reduction factor

$v_{c}$ : Effectiveness factor for concrete compressive strength

$\rho_{c}: \quad$ Unit weight of concrete

$\rho_{\mathrm{o}}$ : $\quad$ Reference value for unit weight of concrete $\left(=2300 \mathrm{~kg} / \mathrm{m}^{3}\right)$

$\rho_{\mathrm{vf}}: \quad$ Transverse reinforcement ratio

$\sigma_{x}: \quad$ Axial stress normally applied to interfacial failure plane

$\sigma_{\mathrm{eq}}: \quad$ Equivalent normal compressive stress $\left(=\rho_{\mathrm{vf}} f_{\mathrm{y}}+\sigma_{x}\right)$

$\tau_{n}: \quad$ Shear friction strength

$\left(\tau_{n}\right)_{\max }:$ Upper limit for shear friction strength

$\phi^{\prime}$ : $\quad$ Friction angle of concrete along construction joint.

\section{Data Availability}

The data used to support the findings of this study are available from the corresponding author upon request.

\section{Conflicts of Interest}

The author declares that there are no conflicts of interest regarding the publication of this paper.

\section{Acknowledgments}

This work was supported by the National Research Foundation of Korea (NRF) grant funded by the Korea Government (MSIP) (no. NRF-2014R1A2A2A09054557).

\section{References}

[1] L. Ahmed and A. Ansell, "Direct shear strength of highstrength fibre concrete," Magazine of Concrete Research, vol. 62, no. 5, pp. 379-390, 2010.

[2] P. M. D. Santoa and E. N. B. S. Júlio, "A state-of-the-art review on shear friction," Engineering Structures, vol. 45, no. 1, pp. 435-448, 2012.

[3] K. H. Yang, J. I. Sim, J. H. Kang, and A. F. Ashour, "Shear capacity of monolithic concrete joints without transverse reinforcement," Magazine of Concrete Research, vol. 64, no. 9, pp. 767-779, 2012.

[4] K. A. Harries, G. Zeno, and B. Shahrooz, "Toward an improved understanding of shear-friction behaviour," ACI Structural Journal, vol. 109, no. 6, pp. 835-844, 2012.

[5] N. Randl, "Design recommendations for interface shear transfer in fib model code 2010," Structural Concrete, vol. 14, no. 3, pp. 230-241, 2013.

[6] ACI Committee 318, Building Code Requirements for Structural Concrete (ACI 318-14) and Commentary, American Concrete Institute, Farmington Hills, MI, USA, 2014.

[7] AASHTO, AASHTO LRFD Bridge Design Specifications, American Association of State Highway and Transportation Official, Washington, DC, USA, 7th edition, 2014.
[8] S. J. Kwon, K. H. Yang, Y. H. Hwang, and A. F. Ashour, "Shear friction strength of monolithic concrete interfaces," Magazine of Concrete Research, vol. 69, no. 5, pp. 230-244, 2017.

[9] Y. H. Hwang and K. H. Yang, "Effect of transverse reinforcement on the shear friction capacity of concrete interfaces with construction joint," Journal of Korea Concrete Institute, vol. 28, no. 5, pp. 555-562, 2016.

[10] R. E. Loov and A. K. Patnaik, "Horizontal shear strength of composite concrete beams with a rough interface," PCI Journal, vol. 39, no. 1, pp. 48-69, 1994.

[11] M. A. Mansur, T. Vinayagam, and K. H. Tan, "Shear transfer across a crack in reinforced high-strength concrete," Journal of Materials Civil Engineering, vol. 20, no. 4, pp. 294-302, 2008.

[12] A. F. Shaikh, "Proposed revisions to shear-friction provisions," PCI Journal, vol. 23, no. 2, pp. 12-21, 1978.

[13] J. C. Walraven, J. Frenay, and A. Pruijssers, "Influence of concrete strength and load history on the shear friction capacity of concrete members," PCI Journal, vol. 32, no. 1, pp. 66-84, 1987.

[14] fib, Model Code for Concrete Structures 2010: Special Activity Group 5, Fédération Internationale de Béton, Lausanne, Switzerland, 2013.

[15] A. H. Mattock, "Shear friction and high-strength concrete," ACI Structural Journal, vol. 98, no. 1, pp. 50-59, 2001.

[16] P. M. D. Santos and E. N. B. S. Júlio, "A state-of-the-art review on shear-friction," Engineering Structures, vol. 45, pp. 435448, 2012.

[17] J. Frenay, "Shear transfer across a single crack in reinforced concrete under sustained loading," Report No. 5-85-5, Stevin Laboratory, Department of Civil Engineering, Delft University of Technology, Delft, Netherlands, 1985.

[18] Y. H. Hwang, "Evaluation of concrete shear friction strength considering its unit weight," M.S. thesis, Department of Architectural Engineering, Kyonggi University, Suwon, South Korea, 2016.

[19] L. F. Kahn and A. D. Mitchell, "Shear friction tests with highstrength concrete," ACI Structural Journal, vol. 99, no. 1, pp. 98-103, 2002.

[20] A. H. Mattock, "Shear transfer under monotonic loading: a cross an interface between concrete cast at different times," Report No. SM76-3, University of Washington, Washington, DC, USA, 1976.

[21] A. H. Mattock, L. Johal, and H. C. Chow, "Shear transfer in reinforced concrete with moment or tension acting across the shear plane," PCI Journal, vol. 20, no. 4, pp. 76-93, 1975.

[22] A. Pruijssers and L. G. Liqui, "Shear transfer across a crack in concrete subjected to repeated loading," Report No. 5-85-12, Stevin Laboratory, Department of Civil Engineering, Delft University of Technology, Delft, Netherlands, 1985.

[23] J. C. Walraven and J. Stroband, "Shear friction in highstrength concrete," ACI Structural Journal, vol. 149, no. 17, pp. 311-330, 1994.

[24] E. N. B. S. Júlio, D. Dias-da-Costa, F. A. B. Branco, and J. M. V. Alfaiate, "Accuracy of design code expressions for estimating longitudinal shear strength of strengthening concrete overlays," Engineering Structures, vol. 32, pp. 2387-2393, 2010.

[25] J. Xiao, C. Sun, and D. A. Lange, "Effect of joint interface conditions on shear transfer behaviour of recycled aggregate concrete," Construction and Building Materials, vol. 105, pp. 343-355, 2016.

[26] P. M. D. Santos, E. N. B. S. Júlio, and V. D. Silva, "Correlation between concrete-to-concrete bond strength and the roughness of the substrate surface," Construction and Building Materials, vol. 21, pp. 1688-1695, 2007. 
[27] K. H. Yang, "Shear stress-relative slip relationship at concrete interfaces," Advances in Materials Science and Engineering, vol. 2016, pp. 1-9, 2016.

[28] M. P. Nielsen and L. C. Hoang, Limit Analysis and Concrete Plasticity, Prentice-Hall, London, UK, 2011.

[29] K. K. B. Dahl, "Construction joints in normal and high strength concrete," Report No. R-314, Department of Structural Engineering, Technical University of Denmark, Kongens Lyngby, Denmark, 1994.

[30] O. C. Choi, S. S. Cho, G. S. Hong, I. Y. Chung, and Y. S. Shin, "Interfacial shear transfer characteristics of concrete joints," Journal of the Architectural Institute of Korea, vol. 10, no. 8, pp. 89-96, 1994.

[31] fib, "Structural connections for precast concrete buildings: guide to good practice," Fédération Internationale de Béton, Lausanne, Switzerland, 2008.

[32] A. Belarbi and T. T. C. Hsu, "Constitutive laws of softened concrete in biaxial tension-compression," ACI Structural Journal, vol. 92, no. 5, pp. 562-573, 1995.

[33] K. N. Rahal, "Shear-transfer strength of reinforced concrete," ACI Structural Journal, vol. 107, no. 4, pp. 419-426, 2010.

[34] G. H. Givens and J. A. Hoeting, Computational statistics, Wiley, New York, NY, USA, 2005. 


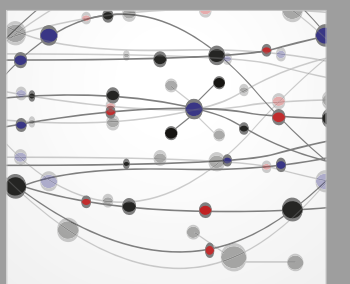

The Scientific World Journal
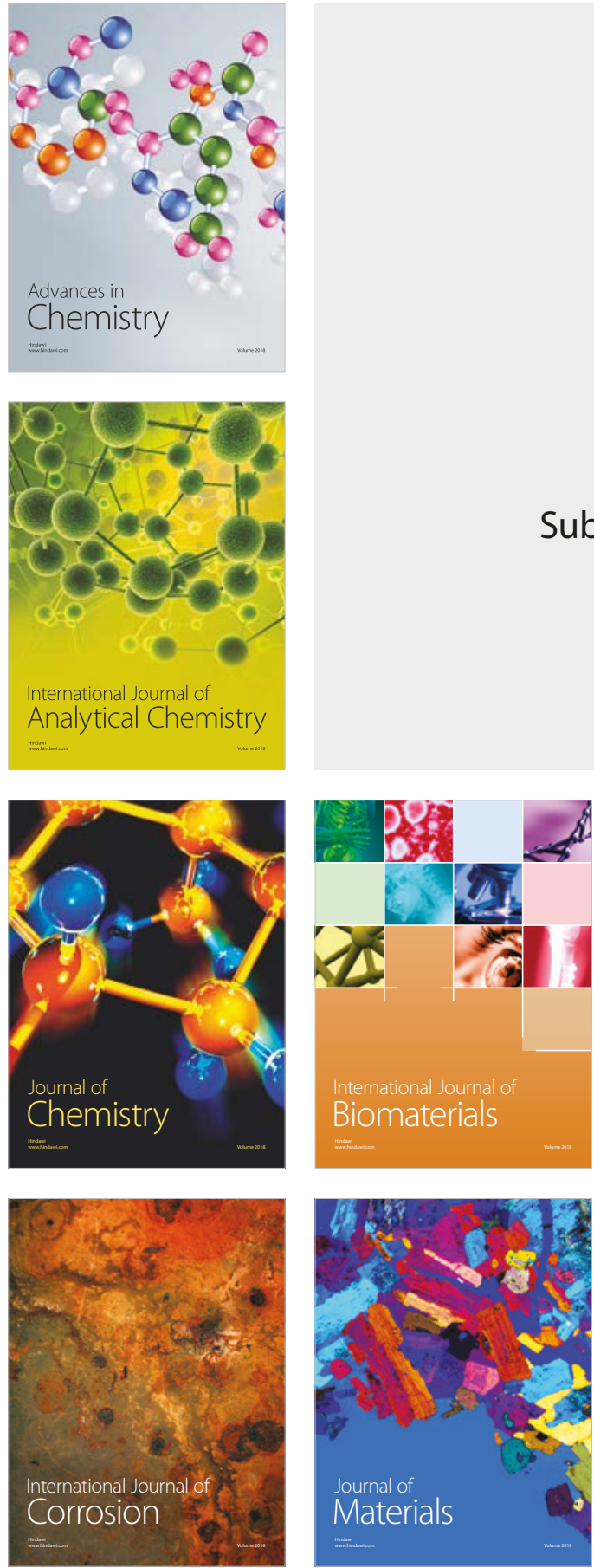

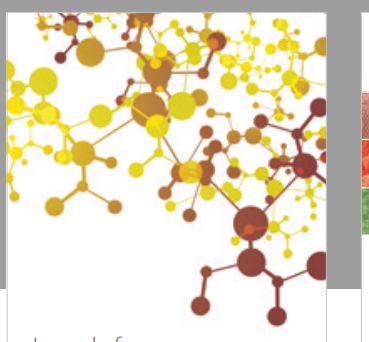

Journal of

Applied Chemistry
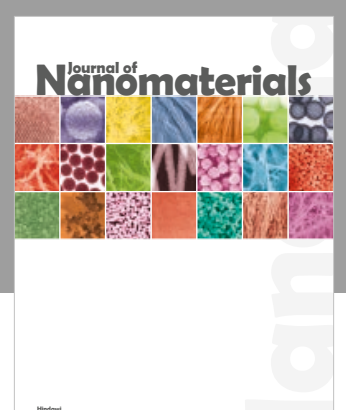

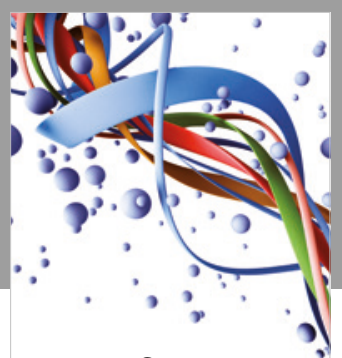

Scientifica

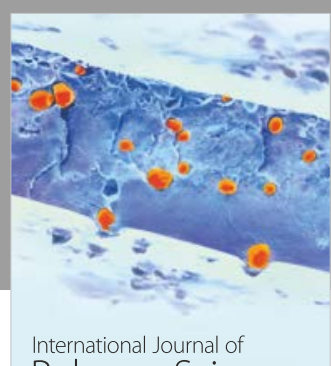

Polymer Science

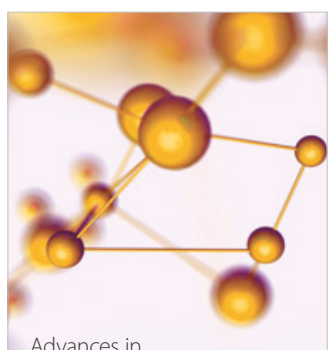

Physical Chemistry
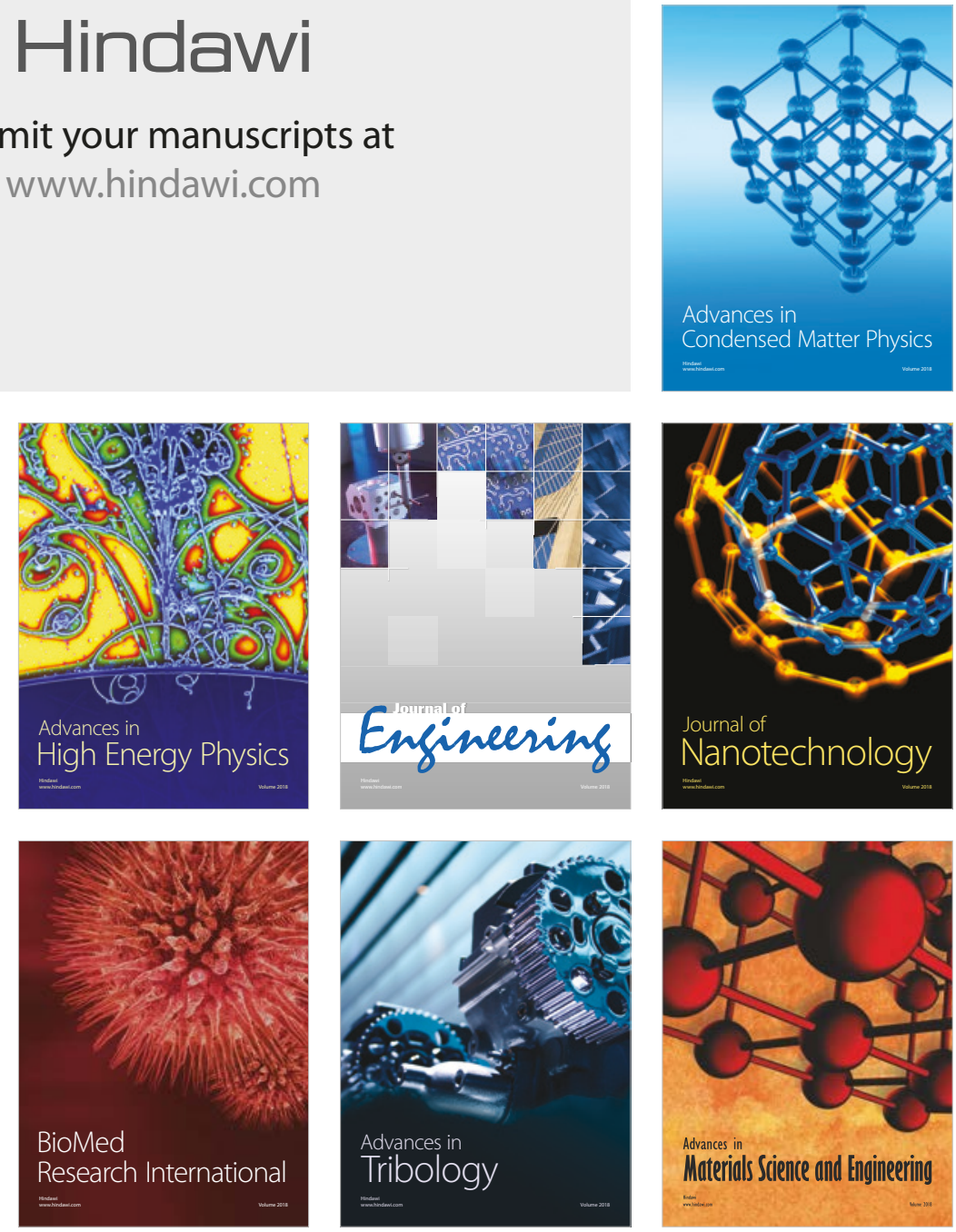